\title{
Prison or psychiatric hospital?
}

\section{Dr. John Bearcroft, in collaboration with}

Mary D. Donovan, reports on an interesting investigation carried out at Long Grove Hospital, which serves part of East London, to discover what kind of men are being referred by prisons and courts for psychiatric assessment.

Many more people than before have been referred for psychiatric reports from courts and prisons since the Mental Health Act came into force in 1960. But since Long Grove Hospital, which serves part of the East London area, seemed to have a particularly high increase in admissions of this sort, we decided to make a study of them. It was possible that this increase in numbers was a particular feature of London. We had found earlier (with D. J. West and A. Smith) that magistrates tend to remand offenders for psychiatric reports more often in prison than on bail. The choice

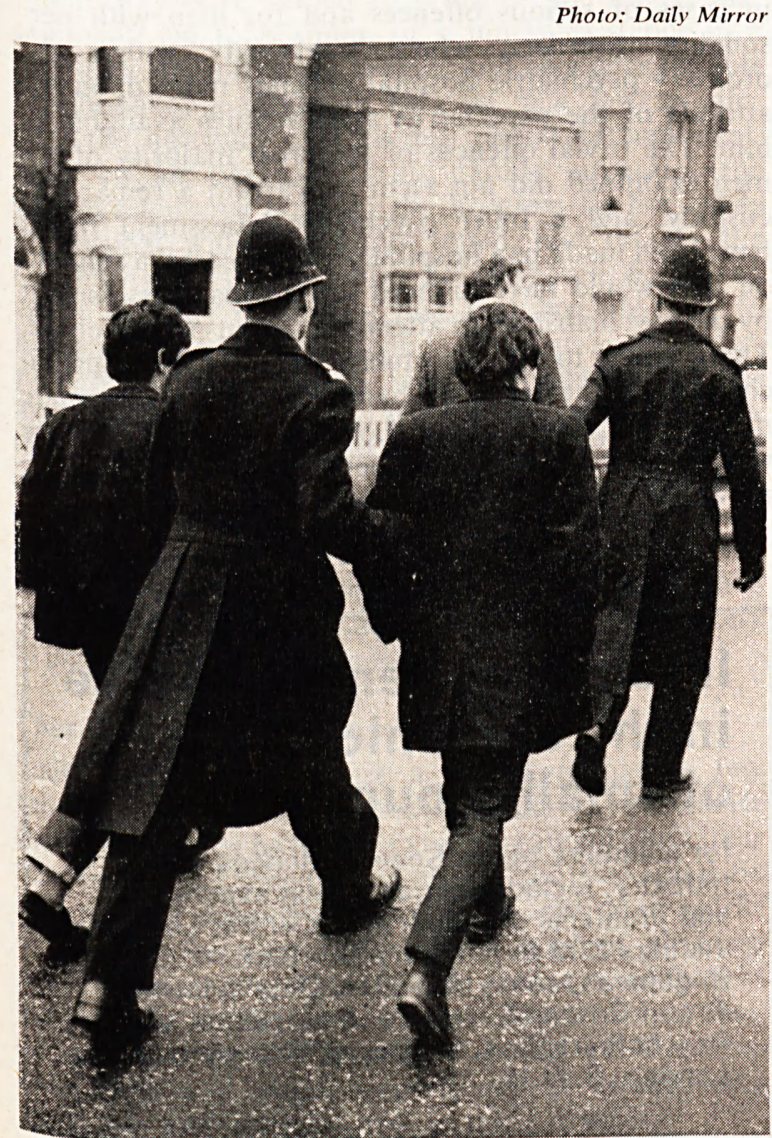

seems to depend more on social than on psychiatric grounds, since men who were homeless or who had committed offences of violence or against property were more likely to be remanded in custody. The number referred for reports to out-patient departments still seemed to be small.

The aim of our investigation was to discover what sort of men were being referred for reports. We particularly wanted to know their diagnosis, social background, the proportion needing hospital admission, whether that admission could have been arranged without the court, whether these people were very different from the ordinary hospital admissions and whether they needed any special nursing care.

In 1963 there were 146 referrals of men to the hospital; as some were referred more than once, there were actually 139 men. 81 had a previous history of psychiatric illness, 34 had shown disturbed behaviour in court and 31 in prison. The most usual diagnosis was either schizophrenia or a personality disorder and more than one diagnosis was often made for a single person. Some of the men, who had not been obviously ill beforehand, became acutely disturbed when they were arrested or in prison. Three-quarters of them had a history of previous criminal activity and though this was mostly of nuisance value only, many of these men had spent periods in prison. The current offences were mostly trivial, such as stealing milk or bread, vagrancy or loitering. This was particularly true of the schizophrenics, who made up 42 per cent of the cases.

Many of the men had left home and one-third were born outside this country, including 12 per cent who were from Eire. These men often had great cultural difficulties. Sixty per cent were homeless at the time of the offences and those who did not have homes often lived in other areas, but had been charged in East London.

\section{History of violence}

Eighty per cent of the men examined were recommended to come into hospital and 8 per cent to have out-patient treatment. Four were admitted to Broadmoor Hospital because of a history of violence. Twothirds of the total $(90$ men) were admitted to Long Grove Hospital and these were compared with a similar number of consecutive male admissions, who had not come from courts or prisons.

It was found that three-quarters of the ordinary admissions came informally, whereas only one-third of the offenders did so. There were more schizophrenics in the prison group and more personality disorders, including alcoholics, among the others. Comparing the schizophrenics in the two groups, the offenders were more geographically mobile-they had more often been in other hospitals and had drifted into East London. There were many immigrants in both groups and a larger proportion of the immigrant 
offenders were homeless. The offenders tended more often to come from a broken home, to be without family support and therefore to stay in hospital longer.

The area served by Long Grove Hospital is one of social disorganisation and it is known that psychiatric disorder is more common in areas like this. One of the reasons is that schizophrenics and men with personality disorders find it difficult to live with their families and tend to drift to areas where the social pressures are minimal.

Since the Mental Health Act, large numbers of longstay patients, including many chronic schizophrenics, have left psychiatric hospitals. The local authority services for them are still not well enough developed to supervise these patients adequately in the community or to cope with the amount of disturbed behaviour and social distress involved. In the case of this hospital, many readmissions are partly due to lack of hostel accommodation of a reasonable standard in the community, though our readmission rate is very close to the national average. Some psychiatrists, including H. R. Rollin, believe that the increase in offenders found to be psychiatrically ill is due to the recent 'Open Door' policy of psychiatric hospitals. But this study shows there are also other factors involved, including the role of the police and the attitude of the public.

It is widely felt that there should be more facilities for treating these problems and a special villa has been set aside for this purpose at Long Grove Hospital.

\section{Role of police}

One aspect of the problem which came to light during this study was the role of the police and the courts in dealing with the mentally disordered in the East End of London. There seemed to be a tendency to use the Remand Prison at Brixton in much the same way as Observation Wards were used in the past, and to remand in custody for trivial offences some homeless men who were psychiatrically ill, were obviously so when examined in prison and were readily recognised to be ill by a social worker with some training in psychiatry.

In general, the police were aware that a man had a previous psychiatric history at the time of the offence. In their statements to the courts, they described the behaviour of the man, and often the nature of his offence as 'disturbed', so that it was clear that they were considering mental illness as a factor. In fact, the police seemed to be an integral part of the service for the mentally ill in East London. They were often called in by relatives or neighbours because of a disturbance or because of abnormal behaviour. This occurred even in cases where the patient and his family were already in contact with the local authority mental health department. Rarely did the police seem to look for help from the general practitioner, the mental welfare officer, or a psychiatrist before charging the man-a procedure which is often used in some areas. In discussing these matters with the police, it seems that they find difficulty in getting men admitted to hospital directly in the London area, so that where they are able to charge him they prefer this procedure, presuming that he will be remanded for a psychiatric report.

\section{Problem for magistrates}

When the case reaches court, the magistrates are commonly faced with an apparently insoluble problem. Psychiatric illness is often obvious because of the history, the nature of the offence, and the man's demeanour in court. The courts in this area make little use at this stage of the mental welfare officers or psychiatrists, both of whom could be available at short notice during court hours. The usual course is a period of remand, which, especially for the homeless and disturbed, seems too often to be in prison. Remand on bail may not seem appropriate to magistrates, but it would be possible for some of these men to be remanded to hospital or else to have a temporary adjournment, in order to get a psychiatric assessment. Neither of these procedures is anything but rarely used.

\section{Need for changes}

A period of remand in prison seems more reasonable in cases of serious offences and for men with personality disorders, where treatability within the ordinary psychiatric hospital depends more upon the attitude of the psychiatrist and facilities available to him. The trivial offences of the great majority of the men examined did not seem to warrant a remand in custody, and a fuller psychiatric assessment might have been made in a hospital. In some cases, a remand on bail would have allowed an adequate assessment by the psychiatric team attending an out-patient clinic. There seems to be opportunity here for some useful changes in the ways of handling these unfortunate men in the East End of London. This will require much closer co-operation between the law and the psychiatric services in the area.

\section{Intensive evening course in the dynamics of small groups}

for members of the Social Sciences and Industry; includes Study Group experience and problems of leadership. Central LondonJanuary 23rd to February 3rd, 1967.

25 guineas, some bursaries. Details from Group Course Secretary, Association of Psychotherapists, 411 Upper Richmond Road, London, S.W.15 